\title{
Correction to: EPSM 2019, Engineering and Physical Sciences in Medicine
}

\section{8-30 October 2019, Perth, Australia}

Published online: 31 January 2020

(c) Australasian College of Physical Scientists and Engineers in Medicine 2020

\section{Correction to: Phys Eng Sci Med} https://doi.org/10.1007/s13246-019-00826-6

The authors of abstract P038 Clinical quality assurance of 3D printed patient specific radiotherapy devices should be listed as:

P H Charles ${ }^{1,2,3}$, A G Livingstone ${ }^{4}$, T Kairn ${ }^{2,4}$, S B Crowe $\mathrm{C}^{1,2}$

${ }^{1}$ Herston Biofabrication Institute, Brisbane, Australia. ${ }^{2} \mathrm{Sci}-$ ence and Engineering Faculty, Queensland University of Publisher's Note Springer Nature remains neutral with regard to jurisdictional claims in published maps and institutional affiliations.

(Scott.Crowe@health.qld.gov.au). ${ }^{3}$ Australian College of Physical Scientists and Engineers in Medicine, Australia. (Paul.Charles@health.qld.gov.au [Presenting author]). ${ }^{4}$ Radiation Oncology, Royal Brisbane and Women's Hospital, Australia

Technology, Brisbane, Australia.

The original article can be found online at https://doi.org/10.1007/ s13246-019-00826-6. 